Article

\title{
A Reference-Model-Based Neural Network Control Method for Multi-Input Multi-Output Temperature Control System
}

\author{
Yuan Liu ${ }^{1,+, \ddagger \mathbb{1}}$, Song $X u^{1,2, \ddagger ®}$, Seiji Hashimoto ${ }^{1, *, \ddagger}$ and Takahiro Kawaguchi ${ }^{1, \ddagger}$ \\ 1 Division of Electronics and Informatics, Gunma University, 1-5-1 Tenjincho, Kiryu 376-8515, Japan; \\ t192d005@gunma-u.ac.jp (Y.L.); xusong0922@outlook.com (S.X.); kawaguchi@gunma-u.ac.jp (T.K.) \\ 2 Department of Electronics and Informatics, Jiangsu University of Science and Technology N.2 Mengxi Road, \\ Zhenjiang 212000, China \\ * Correspondence: hashimotos@gunma-u.ac.jp; Tel.: +81-277-3-1741 \\ + Current address: 5-1067-5 Hishimachi, Kiryu 376-0001, Gunma, Japan. \\ $\ddagger$ These authors contributed equally to this work.
}

Received: 24 September 2020; Accepted: 23 October 2020; Published: 28 October 2020

\begin{abstract}
Neural networks (NNs), which have excellent ability of self-learning and parameter adjusting, has been widely applied to solve highly nonlinear control problems in industrial processes. This paper presents a reference-model-based neural network control method for multi-input multi-output (MIMO) temperature system. In order to improve the learning efficiency of the $\mathrm{NN}$ control, a reference model is introduced to provide the teaching signal for the NN controller. The control inputs for the MIMO system are given by the sum of the output of the conventional integral-proportional-derivative (I-PD) controller and the outputs of the neural network controller.The proposed NN control method can not only improve the transient response of the system, but can also realize temperature uniformity in MIMO temperature systems. To verify the proposed method, simulations are carried out in MATLAB/SIMULINK environment and experiments are carried out on the DSP (Digital Signal Processor)-based experimental platform, respectively. Both results are quantitatively compared to those obtained from the conventional I-PD control systems. The effectiveness of the proposed method has been successfully verified.
\end{abstract}

Keywords: neural network control; multi-input multi-output temperature system; transient response; temperature uniformity

\section{Introduction}

To realize the precise temperature of the industrial process, temperature controllers are widely applied to manage manufacturing processes and operations. The common uses include food processing, packaging machines, and plastic extrusion etc. Their performances can seriously affect product quality, energy consumption, and production cost. In practical application, the proportional-integral-derivative (PID) controller has been widely used for its simple structure and wide applicability, especially in linear systems or first and second order systems [1]. Common methods for determining PID controller parameters are Ziegler-Nichols (ZN) and Cohen-Coon tuning rules, which are widely used in the industry due to their simplicity and ease of implementation, but may easily result in overshoot and weak response damping [2]. Meanwhile, most industrial processes are multi-variable nonlinear systems with big time constants, strong coupling effects, and large time delays. For such controlled objects, only using the conventional PID controller may not satisfy the requirements of the system performance.

In order to ensure the robustness and stability of the controller, many methods have been proposed to improve the performance of the PID controller, such as gain and phase margin [3], pole placement [4], 
and internal model control (IMC) [5]. For canceling the coupling interactions between each channels in multi-input multi-output (MIMO) systems, a verity of decoupling control strategies have been applied, such as inverse Nyquist array(INA) [6], feedforward decoupling control [7], and inverse based decoupling control [8]. These decoupling control methods are to design the decoupler so that the MIMO control system can be divided into multiple single-input single-output (SISO) loops, which allows one to adopt well developed single loop control methods. However, the modeling error may decrease system performance as decoupling is guaranteed under the condition that the precise mathematical model is obtained. The quality of the obtained model depends on many on-site factors, such as the excitation condition and selected identification algorithm [9-11]. In addition, the decoupling control is not enough to reach uniform temperature control in transient state without adjusting the PID parameters in different channels [12].

Considering the complex control rules and controller computation grow exponentially with a number of variables in nonlinear MIMO systems, intelligent control strategies are developed and widely used. Fuzzy logic control, genetic algorithms, and neural networks (NN) are the most promising methods among them [13-15]. NN is known for its great computing power and learning ability to emulate various systems dynamics with a highly parallel structure. Over the past few decades, NN has been successfully applied in many fields such as system modeling, pattern recognition, and signal processing [16-19]. In thermal systems, the NN has been used for heat transfer data analysis, performance prediction, and dynamic modeling etc. [20-23]. It is shown that NN is well suitable to deal with complex nonlinear relationships in control systems. NN helps solve the problem in typical heating system control methods that once the parameters of the control system are designed, they cannot be adjusted while the system is in operation. For a thermal process system with strong nonlinearly, large lag, and strong coupling, an adaptive system can improve control performance in terms of the transient response and overshoot [24-26].

Our previous research has proposed the NN control method applied to the temperature control system, the proposal has successfully improved the transient response of the single-input single-output (SISO) temperature control system [27,28]. However, many controlled objects are MIMO systems in practical applications, the dynamic uniform temperature of the MIMO system is widely required. In the MIMO temperature control system, the coupling effects and delay time differences make the system much more complex than the SISO temperature control system and courses the temperature difference between each channels. Thus, different from the SISO system control, the control performance of the MIMO system should not only focus on improving transient response and overshoot, more importantly, focus on reducing temperature differences to realize temperature uniformity of different channels. In this paper, we extend the previous $\mathrm{NN}$ control method from SISO to MIMO systems, clearly defining the parameters selection method of the reference model for the complex multi-point control system. Moreover, the coupling effects on the system performance can been effectively suppressed by the NN learning controller without specially designing decoupling compensators.

Based on our previous research, this proposal focuses on the multi-inputs multi-outputs (MIMO) temperature control system to improve the transient response of each channel in the MIMO system and reduce the temperature difference between each channel, realizing the temperature uniformity of the MIMO temperature system. A reference-model-based neural network control method combined with the integral-proportional-derivative (I-PD) controller is proposed. The system is driven by the error signal between the reference model output and real system outputs. The error signal of each channel is used as the teaching signal for the corresponding NN controller. The output of NN controller is added to the I-PD controller output, appropriately adjusting the control input of each channel. The MIMO temperature system is expected to achieve uniform temperature and steady state quickly. The rest of this paper is organized as follows: Section 2 describes the structure of the proposed MIMO control system. The simulation results and experimental results are presented in Sections 3 and 4, respectively. 
Meanwhile, the results are quantitatively compared with those of the I-PD control system. A simple conclusion is given in Section 5 .

\section{Configuration of the MIMO Temperature Control System}

This section describes the configuration of the proposed reference-model-based NN control method in the MIMO control system. In this paper, the MIMO system is simplified as a two-input two-output (2I2O) model. The block diagram of the proposed temperature control system is shown in Figure 1.

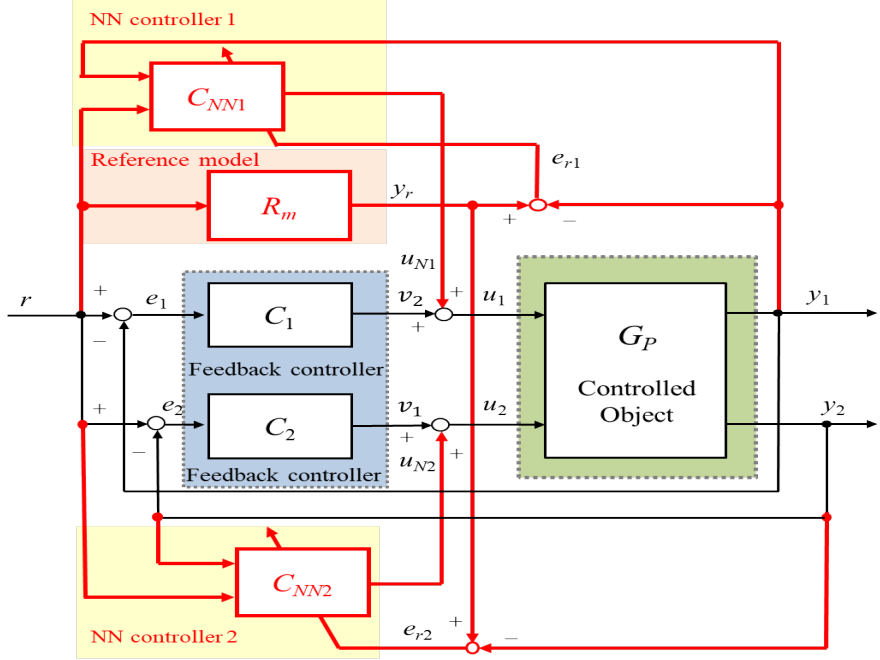

Figure 1. Block diagram of the multi-input multi-output (MIMO) temperature control system.

As shown in Figure 1, the temperature controller consists of two feedback controllers $C_{1}$ and $C_{2}$, a reference model $R_{m}$, and two neural network controllers $C_{N N 1}$ and $C_{N N 2}$. Here, $r$ is the reference of the system, and $y_{1}$ and $y_{2}$ indicate the actual outputs of two channels. $v_{1}$ and $v_{2}$ are the outputs of two feedback controllers $C_{1}$ and $C_{2}$, respectively. $u_{N 1}$ and $u_{N 2}$ indicate the outputs of $C_{N N 1}$ and $C_{N N 2}$, respectively. Thus, the control inputs of the two channels can be respectively indicated by $u_{1}$ and $u_{2}$ which can be expressed as the sum of the outputs of the NN controllers and I-PD controllers. $y_{1}$ and $y_{2}$ represent the inputs and outputs of the 2I2O controlled object, respectively. Due to the control object of each channel being a plant with a time delay, the reference model $R_{m}$ can be appropriately designed to provide the ideal temperature output with the same time delay which is the maximum time delay of two channels in the MIMO system. $e_{r 1}$ and $e_{r 2}$ are the errors between the outputs of the system and output of the reference model, respectively, which are the teaching signal for NN. The NN controller adjusts control inputs to compensate for the difference between the reference model output and each channel output. The explanation of the control system is divided into four main parts.

\subsection{MIMO Controlled Objects with Strong Coupling Effects}

The control system is designed based on the MIMO temperature system with a strong coupling influence, the schematic block diagram of the coupled system is shown in Figure 2, where $u_{1}$ and $u_{2}$ are defined as the inputs of channel ch1 and channel ch2, respectively. In addition, $y_{1}$ and $y_{2}$ indicate the output of ch1 and ch2, respectively. The coupling terms between the two channels are obtained as $P_{21}$ and $P_{12}$, respectively. In this proposal, the controlled objects can be defined as a first-order plus time delay (FOPTD) system expressed as Equation (1) [29]. The step response characteristics of the controlled object is shown in Figure 3, where $\tau$ is time delay, $K$ is the steady-state gain, and $T$ is the time constant.

$$
P(s)=\frac{K}{T s+1} e^{-\tau s}
$$




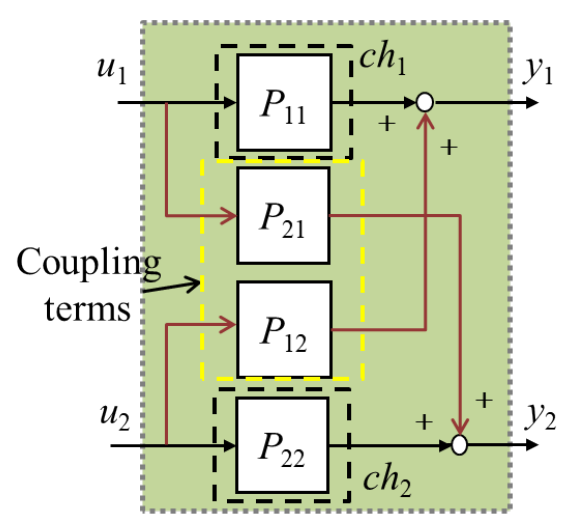

Figure 2. Block diagram of the two-input two-output (2I2O) controlled object.

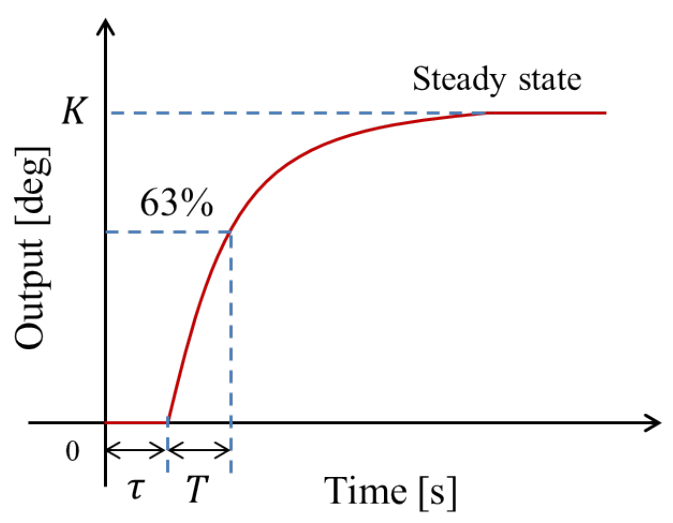

Figure 3. Step response of FOPTD plant.

\subsection{Conventional I-PD Controller}

Considering that the NN controller needs time to train its parameters for getting expected outputs, it will mainly act after training. Thus, the conventional I-PD controllers as the feedback controllers are designed for each channel to eliminate the proportional and derivative kick appeared during the set-point change and reduce the undesirable overshoot of the controlled variable [30]. The block diagram of the conventional I-PD controller is shown in Figure 4. For each I-PD controller parameters of the system, $K_{p n}$ is the proportional gain and $T_{i n}$ is the integral time constant. $T_{d n}$ represents the derivative time constant, where $n=1,2$. They are related to the plant parameters $(K, T$, and $\tau)$ as described above. In addition, $\mu$ represents the low-pass filter gain of the derivative term for reducing the high-frequency gain and noise. The feed-forward gain $K_{f}$ is added to decide the system response speed $\left(K_{f}=0\right.$ : slow; $K_{f}=1$ : fast $)$.

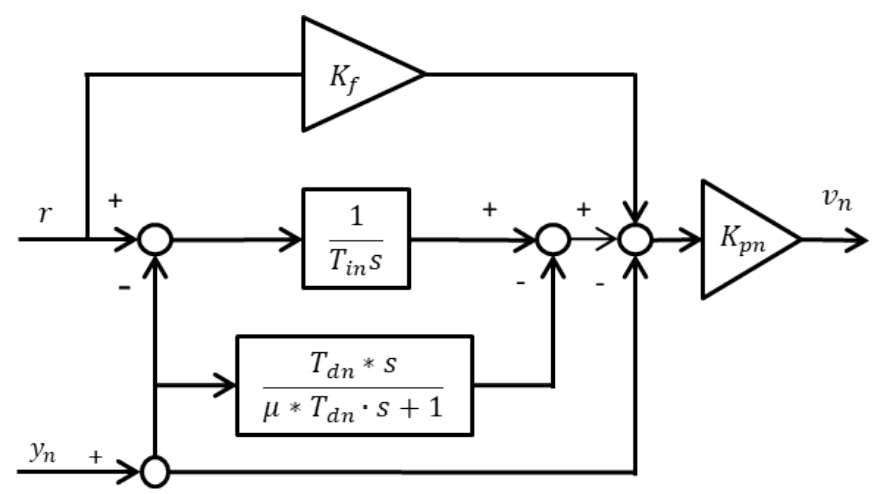

Figure 4. Block diagram of the integral-proportional-derivative (I-PD) controller. 
For the industrial PID controller tuning, Ziegler-Nichols tuning rules are recognized and widely applied in actual control systems. The robustness and stability of the controllers are ensured. The parameters of two I-PD controllers $C_{1}$ and $C_{2}$ are calculated based on this tuning rule as Equations (2)-(4).

$$
\begin{aligned}
& T_{i 1}=2 \tau_{11} ; T_{i 2}=2 \tau_{22} \\
& T_{d 1}=0.5 \tau_{11} ; T_{d 2}=0.5 \tau_{22} \\
& K_{p_{1}}=\frac{1.2 T_{11}}{K_{11} * \tau_{11}} ; \quad K_{p_{2}}=\frac{1.2 T_{22}}{K_{22} * \tau_{22}} .
\end{aligned}
$$

\subsection{Multi-Layer NN Controller}

In order to realize the uniform temperature of different channels, a multi-layer NN controller is introduced into each channel of the control system for the reference model output tracking. In the proposed system, each NN controller has one input layer with two neurons, one hidden layer with 10 neurons, and one output layer with one neuron. Thus, the structure of each multi-layer NN controller can be described as 2-10-1. Figure 5 illustrates the multi-layer neural network controllers.

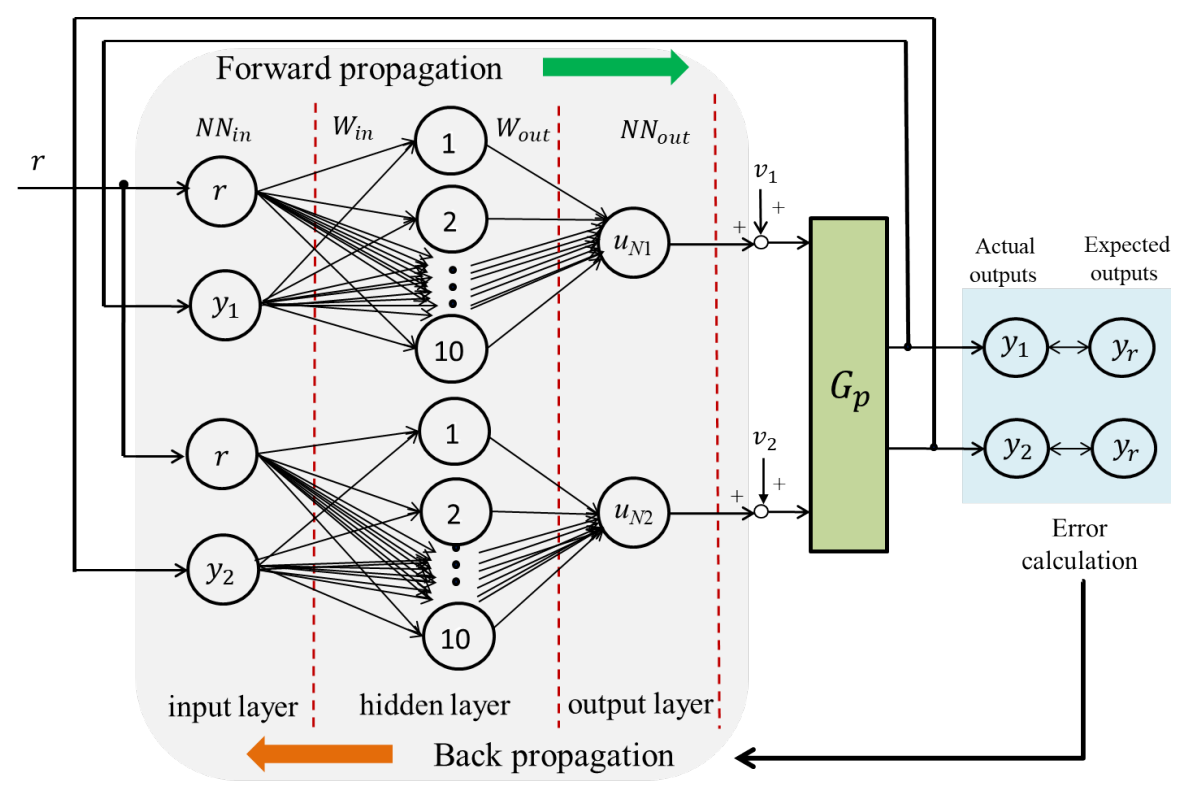

Figure 5. Structure of the multi-layer neural network controllers.

In this system, the reference value of the system $r$ and $y_{1}$ (the output of ch1) are set as the input signals of the NN controller1, $r$ and $y_{2}$ (the output of ch2) are set as the input signals of the NN controller2. For each controller, two inputs are transmitted in the forward direction through the network. The composition of the learning process of the network is by forward propagation and back propagation [31]. Neural network calculates and store intermediate variables from the input signals to the output signals, which is expressed as Equation (5):

$$
N N_{\text {out }}=f\left(W_{\text {out }} * f\left(W_{\text {in }} * N N_{\text {in }}+b_{1}\right)+b_{2}\right)
$$

For each NN controller, $N N_{\text {in }}$ is the input vector and $N N_{\text {out }}$ is the output vector. $W_{\text {in }}$ and $W_{\text {out }}$ are connection weights of neurons. $b_{1}$ is the bias of the hidden layer neurons, $b_{2}$ is the bias of the output layer neurons, and $f(*)$ is the activation function.

For training the network, the back propagation algorithm is used to update the weights and biases. Through this process, each NN controller constantly adjust its outputs $u_{N 1}$ and $u_{N 2}$ for achieving the minimum error between the reference model output and actual outputs of two channels in 
this system. Considering one of the NN controllers, a neuron in the output layer is called neuron $j$ (here $j=1$ ). The error at the output of the neuron $j$ for $n$th iteration is defined by Equation (6). In the backward process, weights on the connections between all layers will be updated to minimize the error between target and output until the optimum weights are found [32]. Therefore, the total error is the sum of $e_{j}$ for all neurons in the output layer, as given in Equation (7):

$$
\begin{gathered}
e_{j}(n)=y_{r}(n)-y_{j}(n) \\
\varepsilon(n)=\frac{1}{2} \sum_{j} e_{j}^{2}(n)
\end{gathered}
$$

where the reference model output $y_{r}$ is the expected output for neuron $j$ and $y_{j}(n)$ is the actual outputs of two channels. The output for the neuron $j$ can be expressed as Equation(8), where $k=10$ is the number of inputs from the hidden layer. Here, $W_{j 0}$ equals the bias $b_{j}$ applied to the neuron $j$ :

$$
y_{j}(n)=f\left(\sum_{i=0}^{k} W_{j i}(n) y_{i}(n)\right)
$$

The connection weights of the neuron $j$ are updated by the chain rule, and can be expressed in Equation (9), where $\delta_{j}(n)$ represents the local gradient of neuron $j$, given in Equation (10):

$$
\begin{gathered}
\frac{\partial \varepsilon(n)}{\partial W_{j i}(n)}=\delta_{j}(n) y_{i}(n) \\
\delta_{j}(n)=-e_{j}(n) f^{\prime}\left(\sum_{i=0}^{k} W_{j i}(n) y_{i}(n)\right) .
\end{gathered}
$$

Therefore, the weight $w_{i j}$ is updated by adopting the gradient descent, expressed as Equation (11). The correction $\Delta W_{i j}$ ensures $w_{i j}$ changes in a way that always decreases the error, given in Equation (12), where $\alpha$ represents the learning rate of the back propagation:

$$
\begin{gathered}
W_{j i}(n+1)=W_{j i}(n)+\Delta W_{i j}(n) \\
\Delta W_{i j}(n)=-\alpha \frac{\partial \varepsilon(n)}{\partial W_{j i}(n)} .
\end{gathered}
$$

The neuron bias connection for the neuron $j$ is adjusted by $\delta_{j}(n)$ during training, as given in Equation (13), where $\beta$ is the training gain of the bias:

$$
b_{j}(n+1)=b_{j}(n)+\beta \delta_{j}(n) .
$$

In order to accelerate the training speed and solve the vanishing problem in the NN controller, the rectified linear unit (ReLU): $f(x)=\max (0, x)$ is used as the activation function [33]. The derivative of the function is given in Equation (14):

$$
f^{\prime}(x)= \begin{cases}1, & x \geq 0 \\ 0, & x<0\end{cases}
$$

\subsection{Reference Model}

In the reference-model-based NN control structure, the teaching signal of each NN controller is provided by errors between the reference model output and real plant output. It also helps to prevent over learning of the NN controller. 
For the controller design, time delays in the dynamic systems can be approximated by rational transfer functions. The exponential function can be defined as follows [34]:

$$
e^{x} \approx \lim _{n \rightarrow \infty} \frac{1}{\left(\frac{x}{n}+1\right)^{n}}
$$

In order to save memory and consider trade-off between accuracy and calculation burden, the time delay $e^{-\tau s}$ which is written as $1 / e^{\tau s}$ can be described as the second-order rational approximation in Equation (16):

$$
e^{-\tau s} \approx \frac{1}{\left(\frac{\tau s}{2}+1\right)^{2}}
$$

Then the reference model with time delay can be expressed as Equation (17). Here, $\tau$ and $T$ are delay time and the time constant of the reference model, which are set based on the real system model. It is designed to provide the ideal temperature output with the same time delay $\tau$ which is the maximum time delay of channels in the MIMO system. In addition, the time constant $T$ of the reference model is the smaller time constant in the identified system model. The gain $P_{R M}$ value of 0.01 is added to the plant time constant $T$ for improving the transient response speed of the system:

$$
R_{m}(s)=\frac{1}{T \cdot P_{R M} \cdot s+1} * \frac{1}{\left(\frac{\tau s}{2}+1\right)^{2}} .
$$

\section{Simulation Results}

To verify the efficiency of the proposed control method, the control object is based on a real temperature control system. Figure 6 shows the experimental setup for the multi-input multi-output temperature system with strong coupling effects and large time delays.

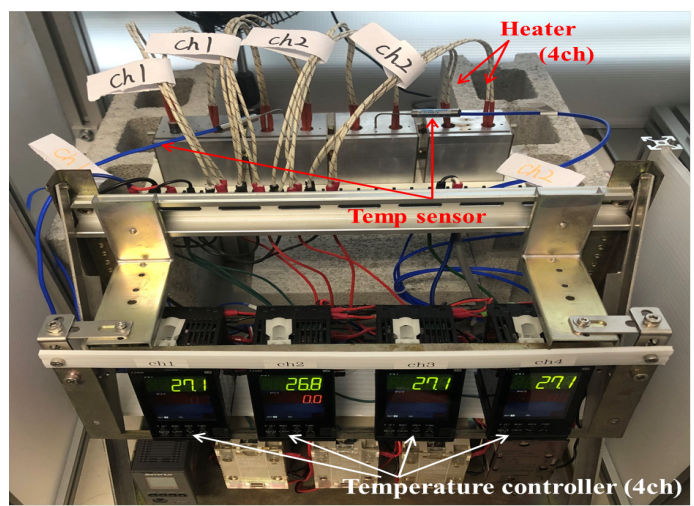

(a) Front view.

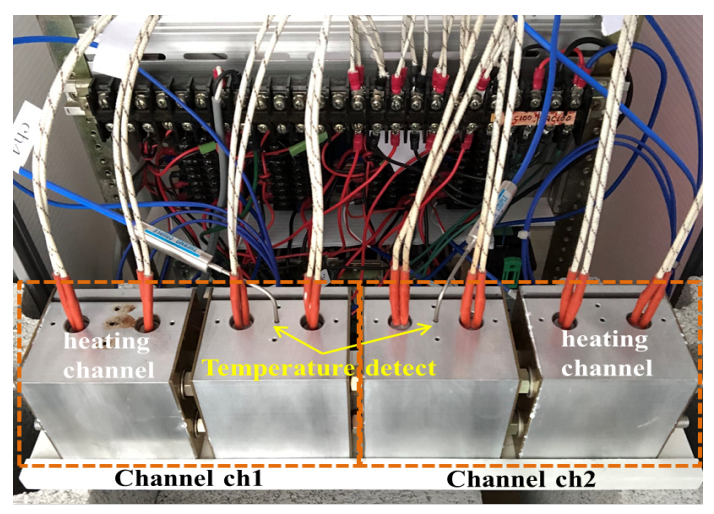

(b) Rear view.

Figure 6. Experimental setup.

\subsection{Experimental Setup and System Identification}

This system has four coupled aluminum blocks, the size being $60 \times 60 \times 50(\mathrm{~mm})$. As shown in Figure $6 \mathrm{~b}$, they are arranged in line with the same separation distance by nuts, forming a two-input two-output system with strong coupling and large time delays. The left two blocks as a whole are channel ch1 and the right two blocks as a whole are channel ch2. Channel ch1 and channel ch2 have two heaters of $150 \mathrm{~W}$ (Cartridge Heater, type G2A56, WATLOW, Chiyoda, Japan) and the temperature sensor ( $\mathrm{K}$ type thermocouple, RKC, Tokyo, Japan), respectively. The temperature sensor transforms the temperature $\left(0-400^{\circ} \mathrm{C}\right)$ into the output voltage (0-10 VDC). They are placed inside of holes with a depth of $30[\mathrm{~mm}]$ (close to the inner center of aluminum blocks). The heaters are controlled by the solid-state relay (SSR, type G3PE-245BL, Omorn, Tokyo, Japan), which is driven by the pulse width modulation (PWM). The temperature is controlled by changing the duty ratio of the PWM 
signals. A digital signal processor (DSP, DS1104 R\&D Controller Board, dSPACE Japan, Tokyo, Japan) is implemented as the temperature controller. The sampling time is set as 0.1 [s]. Although the SSR is a nonlinear element for the relay based on the PWM duty signal, it can be considered as the gain if the switching frequency of the relay is sufficiently large in comparison to the control bandwidth of the controlled object. In our system, the control bandwidth is $\frac{1}{2 \pi * P_{R M} * T}=0.0064[\mathrm{~Hz}]\left(P_{R M} * T\right.$ is the reference model time constant), while the PWM frequency is $10[\mathrm{~Hz}]$. Therefore, SSR can be handled as a linear factor.

The step signal ( $20 \%$ PWM duty cycle) is added to ch1 and ch2, in order. The heaters of the ch1 and heaters of ch2 are actuated, respectively. The ambient temperature during the performed identification experiments was $28^{\circ} \mathrm{C}$. The controlled object of the temperature control system is identified from the input-output(step response) measured data. The ARX (auto-regressive with eXogenous) model based on the least-squares criterion is applied to estimate the system transfer functions in MATLAB. The following Equation (18) shows the form of the ARX model, where $u(k)$ is the system inputs, $y(k)$ is the system outputs, $n_{k}$ is the system delay, and $e(k)$ is the system disturbance:

$$
A(q) y(k)=B(q) u\left(k-n_{k}\right)+e(k) .
$$

In Equation (18), $A(q)$ and $B(q)$ are given as follows:

$$
\begin{gathered}
A(q)=1+a_{1} q^{-1}+\cdots+a_{n_{a}} q^{-n_{a}} \\
B(q)=b_{1} q^{-1-n_{k}}+\cdots+b_{n_{b}} q^{-n_{b}-n_{k}}
\end{gathered}
$$

where $n_{a}$ and $n_{b}$ are the orders of polynomial $A(q)$ and $\mathrm{B}(q)$, respectively. The parameters of $A(q)$ and $B(q)$ are determined using the least squares method that minimizes the quadratic prediction error criteria. In MATLAB, the identified discrete-time model is transformed into the continuous-time model and model order is reduced by balanced realization, obtaining the identified system model in the form of first-order plus time delay $[35,36]$. The performance parameter used for validating the identified model is the percentage of fit as the following expression (21), where $y(k)$ is the actual output, $\hat{y}(k)$ is the model output, and $\bar{y}(k)$ is the mean of the actual output:

$$
\operatorname{Fit}(\%)=\left(1-\frac{\sqrt{\sum_{k=1}^{N}[\hat{y}(k)-y(k)]^{2}}}{\sqrt{\sum_{k=1}^{N}[y(k)-\bar{y}(k)]^{2}}}\right) \times 100 \% .
$$

The identification results of the coupling terms are shown in Figure 7 and the estimation fit in results shows that the accuracy of the estimated model is above $95 \%$.
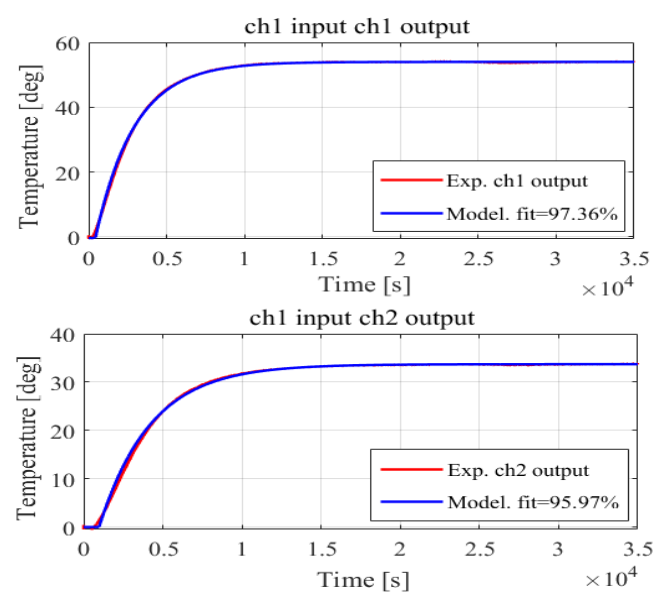

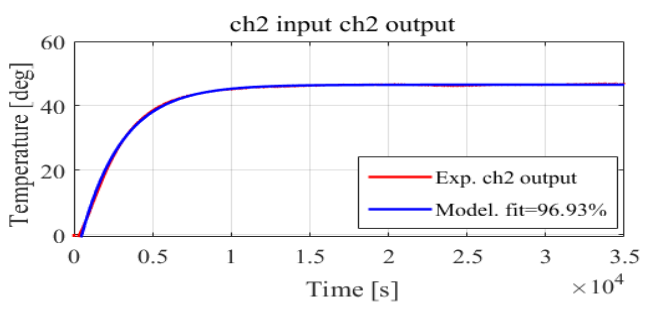

ch2 input ch1 output

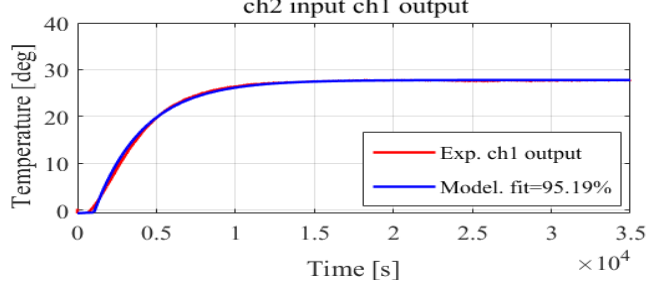

Figure 7. System identification results. 
Thus, the identification results can be finalized as (22). The system controller parameter design, system simulation, and experiments are all based on the identified plant transfer functions:

$$
G_{p}(s)=\left[\begin{array}{ll}
P_{11} & P_{12} \\
P_{21} & P_{22}
\end{array}\right]=\left[\begin{array}{ll}
\frac{2.7502}{2482.4 s+1} e^{-431 s} & \frac{1.4614}{3085.1 s+1} e^{-1042 s} \\
\frac{1.7352}{3195.9 s+1} e^{-973 s} & \frac{2.3937}{2588.6 s+1} e^{-464 s}
\end{array}\right] .
$$

\subsection{Simulation Results}

According to the identified system model, the gains of two I-PD controllers are determined by the Ziegler-Nichols method, as described above. The gains of the I-PD controller $\left(C_{1}\right)$ are $K_{p 1}=2.5146$, $T_{i 1}=861.5$, and $T_{d 1}=215.375$. The gains of the I-PD controller $\left(C_{2}\right)$ are $K_{p 2}=2.7968, T_{i 2}=927.98$, and $T_{d 2}=231.995$. In addition, the reference model $R_{m}(s)$ is given as (23). Here, $P_{R M}$ is set as 0.01:

$$
R_{m}(s) \approx \frac{1}{2482.4 * 0.01 * s+1} * \frac{1}{\left(\frac{464 s}{2}+1\right)^{2}} .
$$

The hyper-parameters of both NN controllers are initialized as follows: The learning rate $\alpha=1 \times 10^{-10}$ and the bias training gain $\beta=1 \times 10^{-5}$. They are determined via the try and error method. The initial biases of each layer are initialized as zero. The weights of the NN controller are initialized to small random values between -1 and 1 .

The simulation is divided into two phases. In the first phase, setting the reference signal to $100{ }^{\circ} \mathrm{C}$, then the temperature of different channels increases from $0{ }^{\circ} \mathrm{C}$ to $100{ }^{\circ} \mathrm{C}$. During this period, the neural network controller completes learning. Then, in the second phase, a repetitive step signal with an amplitude of $5{ }^{\circ} \mathrm{C}$ is added to the reference signals periodically. The offset of the reference signal is $100{ }^{\circ} \mathrm{C}$. In one cycle, the temperature is controlled from $100{ }^{\circ} \mathrm{C}$ to $105^{\circ} \mathrm{C}$, then return to $100{ }^{\circ} \mathrm{C}$. After multiple cycles, the first step response and last step response results in both directions can be obtained. Here, the temperature from $100{ }^{\circ} \mathrm{C}$ to $105^{\circ} \mathrm{C}$ is defined as the positive direction control and the temperature from $105^{\circ} \mathrm{C}$ to $100^{\circ} \mathrm{C}$ is defined as the negative direction control.

Figure $8 \mathrm{a}$ shows the full time response of the control system and (b) shows the results of positive direction control (from $100{ }^{\circ} \mathrm{C}$ to $105{ }^{\circ} \mathrm{C}$ ) and negative direction control (from $105{ }^{\circ} \mathrm{C}$ to $100{ }^{\circ} \mathrm{C}$ ) of the NN control system. From the NN control system results, the first step response is almost the same as the last response, meaning the learning of the $\mathrm{NN}$ control ends at the beginning of the first step. Thus, the NN controllers realize the quick-learning. These results are quantitatively compared with those obtained by the conventional I-PD control with different feed-forward gains $K_{f}=0$ (slow response) and $K_{f}=1$ (fast response). The step-response characteristics of systems are computed from the response data in MATLAB, the rise time of a response is defined as the change in time required for the response to rise from $10 \%$ to $90 \%$ of the desired steady-state response yfinal (here, $105^{\circ} \mathrm{C}$ and $100^{\circ} \mathrm{C}$, respectively). Furthermore,the settling time is defined as the time required for the error between the time response $y(t)$ and yfinal to fall below $5 \%$ of the yfinal. Percentage overshoot is also relative to yfinal.

In the positive direction, two channels of the proposed $\mathrm{NN}$ control system follow the reference model as much as possible. The rise time of ch1 and ch2 in the NN control system is $753.2 \mathrm{~s}$ and $787.9 \mathrm{~s}$, respectively. Compared with that of the I-PD $\left(K_{f}=0\right)$ control system, which is $931.2 \mathrm{~s}$ and $990.1 \mathrm{~s}$, ch 1 and ch 2 has an improvement of $23.6 \%$ and $25.7 \%$, respectively. Compared with that of the I-PD $\left(K_{f}=1\right)$ system which is $459.2 \mathrm{~s}$ and $482.4 \mathrm{~s}$, although the transient response of the I-PD $\left(K_{f}=1\right)$ system is faster, the overshoots of two channels are $2.43{ }^{\circ} \mathrm{C}$ and $2.37{ }^{\circ} \mathrm{C}$, which are about $48.6 \%$ and $47.5 \%$ of the reference value, respectively. The overshoots of two channels in the I-PD $\left(K_{f}=0\right)$ system are $0.51{ }^{\circ} \mathrm{C}$ and $0.4{ }^{\circ} \mathrm{C}$, which are about $10.1 \%$ and $8 \%$ of the reference value, respectively. By contrast, both overshoots of the proposed NN system outputs are zero.

In addition, the settling time of ch1 and ch2 in the NN control system is $2225.1 \mathrm{~s}$ and $2178.4 \mathrm{~s}$. Compared with that of the I-PD $\left(K_{f}=1\right)$ control system which is $3666.3 \mathrm{~s}$ and $3554.5 \mathrm{~s}$, both channels have an improvement of about $42 \%$. Compared with that of the I-PD $\left(K_{f}=0\right)$ control system which is 
$3634.9 \mathrm{~s}$ and $3144.1 \mathrm{~s}$, ch 1 improved by $38 \%$ and ch 2 improved by $31 \%$, respectively. The NN control system was the fastest to reach stable state without overshoots. Simulation results for the temperature from $100{ }^{\circ} \mathrm{C}$ to $105^{\circ} \mathrm{C}$ are presented in Table 1 . The rise time and settling time reflect the transient response and steady-state response speed of the control systems, respectively.

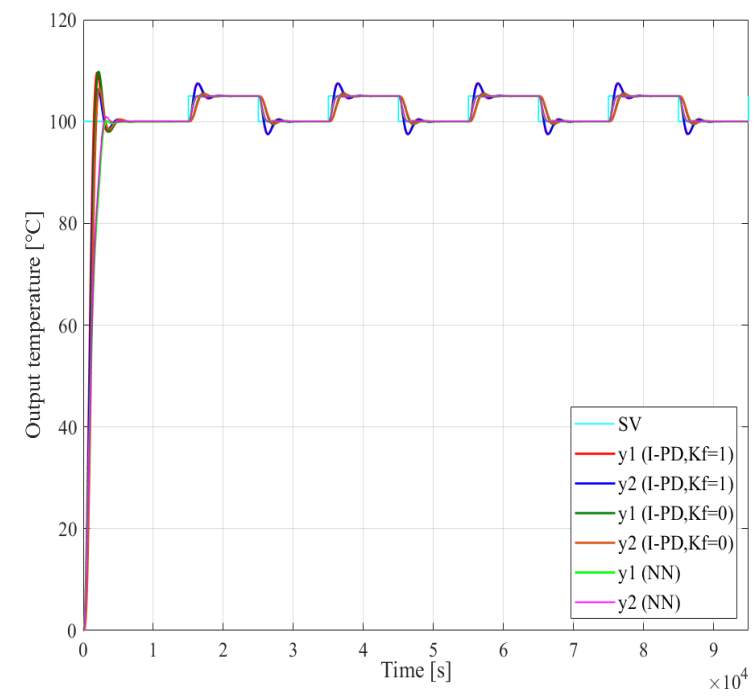

(a) Full time response of the control system.
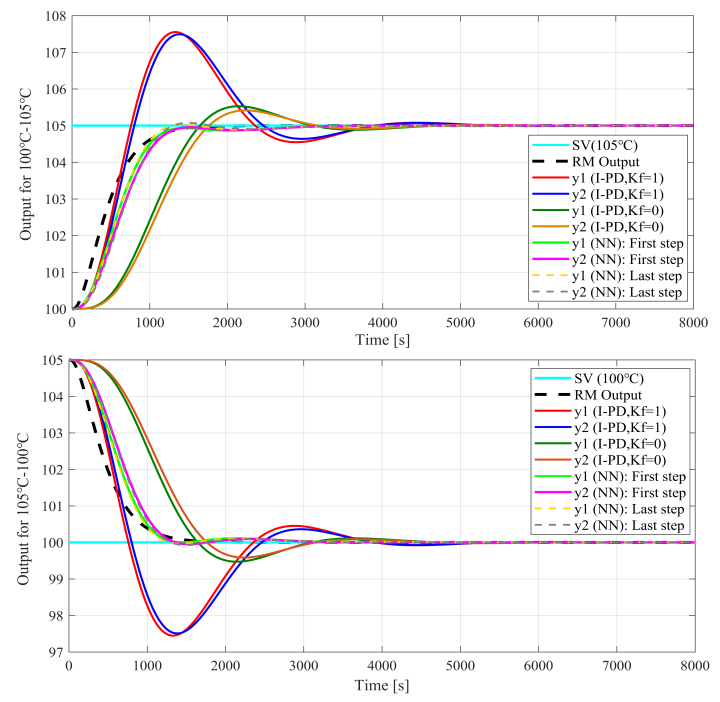

(b) Positive and negative direction control results.

Figure 8. Simulation results. (a) Full time response for the control system. (b) Results of positive direction control for the temperature from $100{ }^{\circ} \mathrm{C}$ to $105^{\circ} \mathrm{C}$ and negative direction control for the temperature from $105^{\circ} \mathrm{C}$ to $100{ }^{\circ} \mathrm{C}$.

Table 1. Comparison of simulation results for time response characteristics $\left(100{ }^{\circ} \mathrm{C}\right.$ to $\left.105^{\circ} \mathrm{C}\right)$.

\begin{tabular}{cccccccc}
\hline $\mathbf{1 0 0}{ }^{\circ} \mathbf{C}$ to $\mathbf{1 0 5}{ }^{\circ} \mathbf{C}$ & Ref & $\mathbf{c h} \mathbf{1}\left(\boldsymbol{K}_{f}=\mathbf{1}\right)$ & $\mathbf{c h} \mathbf{2}\left(\boldsymbol{K}_{f}=\mathbf{1}\right)$ & $\mathbf{c h} \mathbf{1}\left(\boldsymbol{K}_{f}=\mathbf{0}\right)$ & $\mathbf{c h} \mathbf{2}\left(\boldsymbol{K}_{\boldsymbol{f}}=\mathbf{0}\right)$ & $\mathbf{c h} \mathbf{1}(\mathrm{NN})$ & $\mathbf{c h} \mathbf{2}(\mathrm{NN})$ \\
\hline Rise Time (s) & 780.7 & 459.2 & 482.4 & 931.2 & 990.1 & 753.2 & 787.9 \\
\hline Settling Time (s) & 1378.2 & 3663.0 & 3554.5 & 3634.9 & 3144.1 & 2225.1 & 2178.4 \\
\hline Overshoot $(\%)$ & 0 & 48.6 & 47.5 & 10.1 & 8.0 & 0 & 0 \\
\hline
\end{tabular}

In the negative direction, the temperature signal varies from $105{ }^{\circ} \mathrm{C}$ to $100{ }^{\circ} \mathrm{C}$. Response characteristics of different control systems are compared and results are similar to the corresponding results in the positive direction. The rise time of ch1 and ch2 in the NN control system is $726.7 \mathrm{~s}$ and $772.2 \mathrm{~s}$, respectively. Compared with that of the I-PD $\left(K_{f}=0\right)$ control system, which is $931.2 \mathrm{~s}$ and $990.1 \mathrm{~s}$, ch1 and ch 2 has an improvement of $21.9 \%$ and $22 \%$, respectively. Compared with that of the I-PD $\left(K_{f}=1\right)$ system which is $459.2 \mathrm{~s}$ and $482.4 \mathrm{~s}$, although the transient response of the I-PD $\left(K_{f}=1\right)$ system is faster, the overshoots of two channels are $2.43^{\circ} \mathrm{C}$ and $2.37^{\circ} \mathrm{C}$, which are about $48.6 \%$ and $47.5 \%$ of the reference value, respectively. The overshoots of the two channels in the I-PD $\left(K_{f}=0\right)$ system are $0.51{ }^{\circ} \mathrm{C}$ and $0.4{ }^{\circ} \mathrm{C}$, which are about $10.1 \%$ and $8 \%$ of the reference value, respectively. By contrast, both overshoots of the proposed NN system outputs are zero.

Additionally, the settling time of ch1 and ch2 in the I-PD $\left(K_{f}=0\right)$ control system is $3689 \mathrm{~s}$ and $3135.5 \mathrm{~s}$. In the NN control system, it is $2241.3 \mathrm{~s}$ and $2164.5 \mathrm{~s}$, which has an improvement of $39 \%$ and $31 \%$, respectively. Compared with that of the I-PD $\left(K_{f}=1\right)$ control system which is $3669 \mathrm{~s}$ and $3553 \mathrm{~s}$, the NN control system improved by $38.9 \%$ and 39\%. From simulation results, different channels in the NN control system can quickly reach the stable state with no overshoot in contrast to the large overshoots of the I-PD control systems. Simulation results for temperature from $105{ }^{\circ} \mathrm{C}$ to $100{ }^{\circ} \mathrm{C}$ are presented in Table 2 . These results show that the proposed NN control system has improved the temperature control efficiency in both directions. 
Figure $9 \mathrm{a}, \mathrm{b}$, respectively show the temperature differences between ch1 and ch 2 in positive and negative directions, using I-PD control with gains $K_{f}=1,0$ and the proposed NN control.

Table 2. Comparison of simulation results for time response characteristics $\left(105^{\circ} \mathrm{C}\right.$ to $\left.100{ }^{\circ} \mathrm{C}\right)$.

\begin{tabular}{cccccccc}
\hline $\mathbf{1 0 5}{ }^{\circ} \mathbf{C}$ to $\mathbf{1 0 0}{ }^{\circ} \mathbf{C}$ & Ref & $\mathbf{c h 1}\left(\boldsymbol{K}_{f}=\mathbf{1}\right)$ & $\mathbf{c h} \mathbf{2}\left(\boldsymbol{K}_{f}=\mathbf{1}\right)$ & $\mathbf{c h} \mathbf{1}\left(\boldsymbol{K}_{f}=\mathbf{0}\right)$ & $\mathbf{c h} \mathbf{2}\left(\boldsymbol{K}_{f}=\mathbf{0}\right)$ & $\mathbf{c h} \mathbf{1}(\mathbf{N N})$ & $\mathbf{c h} \mathbf{2}(\mathbf{N N})$ \\
\hline Rise Time $(\mathrm{s})$ & 780.7 & 459.2 & 482.4 & 931.2 & 990.1 & 726.7 & 772.2 \\
\hline Settling Time $(\mathrm{s})$ & 1378.2 & 3669.0 & 3552.0 & 3689.0 & 3135.5 & 2241.3 & 2164.5 \\
\hline Overshoot $(\%)$ & 0 & 48.6 & 47.5 & 10.1 & 7.9 & 0 & 0 \\
\hline
\end{tabular}

In the positive direction, the maximum temperature difference of the I-PD control with gains $K_{f}=1$ and $K_{f}=0$ are $0.35{ }^{\circ} \mathrm{C}$ and $0.31{ }^{\circ} \mathrm{C}$, about $7 \%$ and $6.2 \%$ of the reference temperature, respectively. The result of the proposed NN control system is $0.23{ }^{\circ} \mathrm{C}$, about $4.6 \%$ of the reference temperature. The maximum temperature difference of the $\mathrm{NN}$ control system is decreased by $2.4 \%$ and $1.6 \%$, compared to results of I-PD $\left(K_{f}=0\right)$ and I-PD $\left(K_{f}=1\right)$ control systems. Meanwhile, the temperature difference of the NN control drops to $0{ }^{\circ} \mathrm{C}$ in about $2400 \mathrm{~s}$. The time has been shortened by $55 \%$ and $59 \%$ compared with the time for I-PD $\left(K_{f}=1\right)$ and I-PD $\left(K_{f}=0\right)$ control systems, which is about $5300 \mathrm{~s}$ and $5800 \mathrm{~s}$.

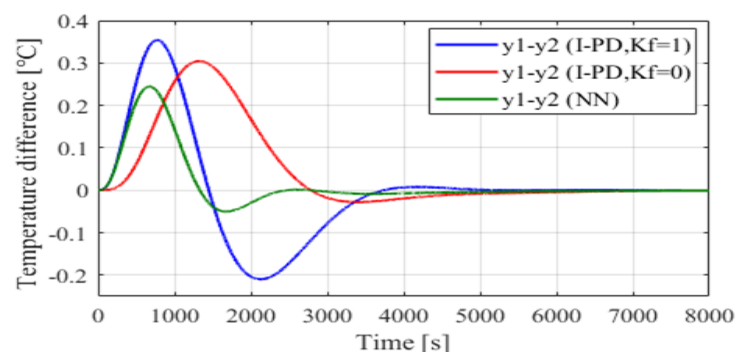

(a) Temperature difference $\left(100^{\circ} \mathrm{C}-105^{\circ} \mathrm{C}\right)$.

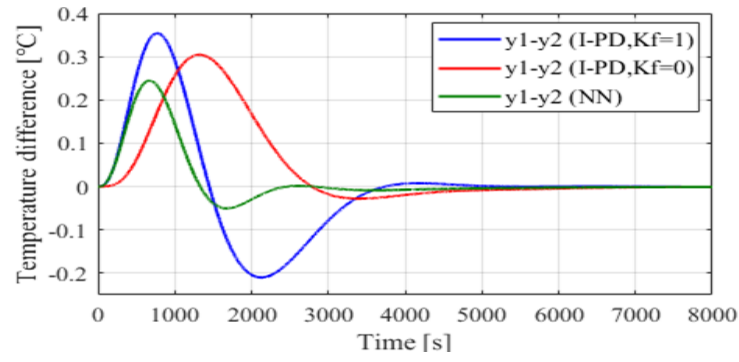

(b) Absolute temperature difference $\left(105^{\circ} \mathrm{C}-100^{\circ} \mathrm{C}\right)$.

Figure 9. Simulation results. (a) Temperature differences between ch1 and ch 2 from $100{ }^{\circ} \mathrm{C}$ to $105^{\circ} \mathrm{C}$.

(b) Absolute temperature differences between ch1 and ch 2 from $105^{\circ} \mathrm{C}$ to $100{ }^{\circ} \mathrm{C}$.

In the negative direction, results are similar to those in the positive direction. The maximum absolute temperature difference of the $\mathrm{NN}$ control system and the I-PD control system with gains $K_{f}=1$ and $K_{f}=0$ are about $0.24{ }^{\circ} \mathrm{C}, 0.34{ }^{\circ} \mathrm{C}$ and $0.31{ }^{\circ} \mathrm{C}$, corresponding to $4.8 \%, 6.8 \%$, and $6.2 \%$ of the reference value. The maximum temperature difference in the NN control system decreased by $1.4 \%$ and $1.6 \%$, when compared to the results of I-PD $\left(K_{f}=0\right)$ and I-PD $\left(K_{f}=1\right)$ control systems. Meanwhile, the temperature difference of the NN control drops to 0 in about $2300 \mathrm{~s}$. The time is shortened by $57 \%$ and $60 \%$ compared to that of I-PD $\left(K_{f}=1\right)$ and I-PD $\left(K_{f}=0\right)$ control systems, which is about $5400 \mathrm{~s}$ and $5700 \mathrm{~s}$. From these simulation results, although the maximum temperature difference between ch1 and ch2 is not suppressed drastically, quick transient response and uniform temperature in different channels can be achieved.

In order to analyze the influences of the coupling terms between different channels, the time response results of the I-PD $\left(K_{f}=1\right)$ control system with coupling and without coupling effects are given in Figure 10, the reference signal is set to $100^{\circ} \mathrm{C}$. The overshoots of the system with coupling terms become bigger, about $11.2 \%$ and $8.4 \%$ of the reference signal. The overshoots of the system without coupling terms are about $9.4 \%$ and $7.8 \%$, respectively. In addition, a slight oscillation is enhanced in both outputs for the coupling effects. From absolute temperature differences of outputs between the control system with coupling effects and without coupling effects, both output temperature differences in the I-PD system are large, with maximum values of about $11.4^{\circ} \mathrm{C}$ and $16.6^{\circ} \mathrm{C}$, respectively. The maximum errors of the $\mathrm{NN}$ control system are about $4.2{ }^{\circ} \mathrm{C}$ and $5.1^{\circ} \mathrm{C}$ in output temperatures. 
The proposed NN control system can effectively weaken the coupling terms influences on the control system outputs.

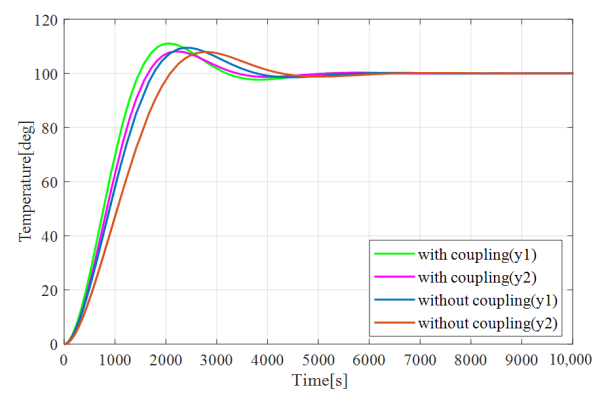

(a) Time response comparison.

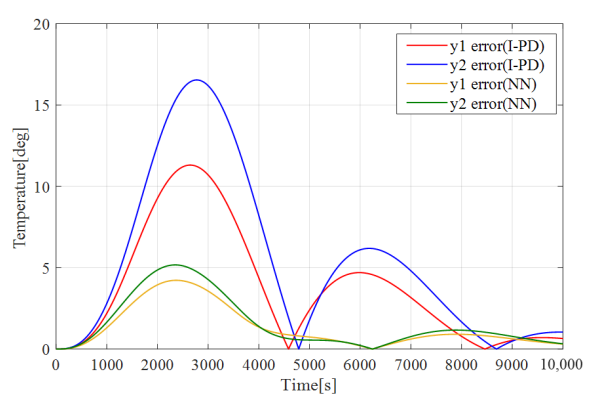

(b) Absolute temperature difference of outputs.

Figure 10. Analysis of coupling effects in the control system. (a) Compare time response results between the control system with coupling effects and without coupling effects. (b) Absolute temperature difference of outputs between the control system with coupling effects and without coupling effects.

\section{Experimental Results}

According to the identified system model introduced in the simulation, experiments with the proposed NN control method are carried out in the real temperature control system. The experimental setup is shown in Figure 6. Experimental conditions are as follows: The room temperature is set at $28{ }^{\circ} \mathrm{C}$, sampling period is $0.1 \mathrm{~s}$, controller sampling bit is 12 bits and the sensor resolution is $0.1^{\circ} \mathrm{C}$. In experiments, the reference temperature is first set to $100^{\circ} \mathrm{C}$, the temperature of two channels is controlled from the room temperature to $100^{\circ} \mathrm{C}$. Then a repetitive step signal with amplitude of $5{ }^{\circ} \mathrm{C}$ is added to the reference periodically. The temperature is controlled from $100{ }^{\circ} \mathrm{C}$ to $105^{\circ} \mathrm{C}$, then return to $100{ }^{\circ} \mathrm{C}$. This process is repeated many times. The temperature increases from the room temperature to $100{ }^{\circ} \mathrm{C}$, defined as the learning period of the $\mathrm{NN}$ controller, and the temperature from $100{ }^{\circ} \mathrm{C}$ to $105^{\circ} \mathrm{C}$ and from $105{ }^{\circ} \mathrm{C}$ to $100{ }^{\circ} \mathrm{C}$ are the control results of the NN control system. For NN learning in the first step, we roughly estimated $\left[u_{N 1}, y_{1}, e_{r 1}, u_{N 2}, y_{2}, e_{r 2}\right] \times 100,000$ steps (sampling time $0.1 \mathrm{~s}$ ) $=$ $6.0 \times 10^{5}$ data is required to complete the learning. For testing the learned $\mathrm{NN}$, one sequence of the step response is needed. Therefore, the same data number is required. Similarly, in the simulation, to verify the control performance of the proposed method, results are compared with those of the I-PD control with gains $K_{f}=1$ (slow) and $K_{f}=0$ (fast).

Figure 11a shows the results for full time response of the control system, and (b) shows the results for the temperature changes in positive and negative directions. As shown in Figure 11b, the I-PD control system with gain $K_{f}=1$ has the fastest transient response speed, but is the slowest to reach the steady state in both directions. For the I-PD control system with gain $K_{f}=0$, both the transient response and steady-state response are slower than the NN control system in both directions.

The time response characteristics of controlled systems are extracted from positive direction and negative direction response data in MATLAB. The response data is loaded, which is an array of response data $y$ and corresponding time vector $t$. The 2 nd-order butterworth digital low-pass filter with a cutoff frequency of $0.05 \mathrm{~Hz}$ (sampling frequency is $10 \mathrm{~Hz}$ ) is applied to eliminate as much of the noise in the data as possible. The response characteristics were calculated from these data using the command "S = stepinfo( $y, t, y f i n a l)$ " in MATLAB. Considering the noise in the data, the last value in $y$ may not have the true steady-state response value. Therefore, the steady-state value (yfinal) should be set as 105 and 100 in the positive and negative direction control, respectively. The response characteristics of controlled systems such as rise time, settling time, and overshoot can be obtained.

In the positive direction, the rise time of ch1 and ch2 in the I-PD $\left(K_{f}=0\right)$ control system is $947.2 \mathrm{~s}$ and $973.1 \mathrm{~s}$, in the NN control system, it is $812.4 \mathrm{~s}$ and $820.6 \mathrm{~s}$, which improved by $14.2 \%$ and $15.7 \%$. The settling time of ch1 and ch2 in the I-PD $\left(K_{f}=0\right)$ control system is $3414.2 \mathrm{~s}$ and $3217.9 \mathrm{~s}$, 
and the NN control system had an improvement of $35.1 \%$ and $31.5 \%$, which is $2217.3 \mathrm{~s}$ and $2204.8 \mathrm{~s}$, respectively. In the I-PD $\left(K_{f}=1\right)$ control system, the settling time of ch1 and ch2 is $3824.3 \mathrm{~s}$ and $3718.6 \mathrm{~s}$. By comparison, the NN control system improved by $42 \%$ and $40.7 \%$. In addition, the overshoots of ch1 and ch2 in the I-PD $\left(K_{f}=1\right)$ control system are $2.01{ }^{\circ} \mathrm{C}$ and $1.92{ }^{\circ} \mathrm{C}$, corresponding to $40.1 \%$ and $38.4 \%$ of the reference. The overshoots of ch1 and ch2 in the I-PD $\left(K_{f}=0\right)$ control system are about $0.69{ }^{\circ} \mathrm{C}$ and $0.53{ }^{\circ} \mathrm{C}$, corresponding to $13.9 \%$ and $10.5 \%$ of the reference. In the $\mathrm{NN}$ control system, the overshoot of ch1 and ch2 are about $0.06{ }^{\circ} \mathrm{C}$ and $0.08{ }^{\circ} \mathrm{C}$, corresponding to $1.3 \%$ and $1.7 \%$ of the reference, much smaller than those in the I-PD control systems.

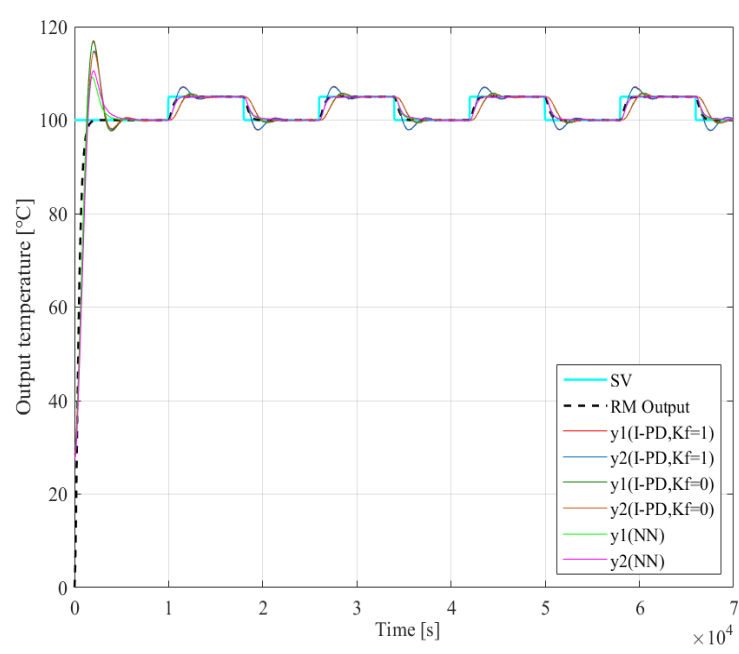

(a) Time response of the controlled system.

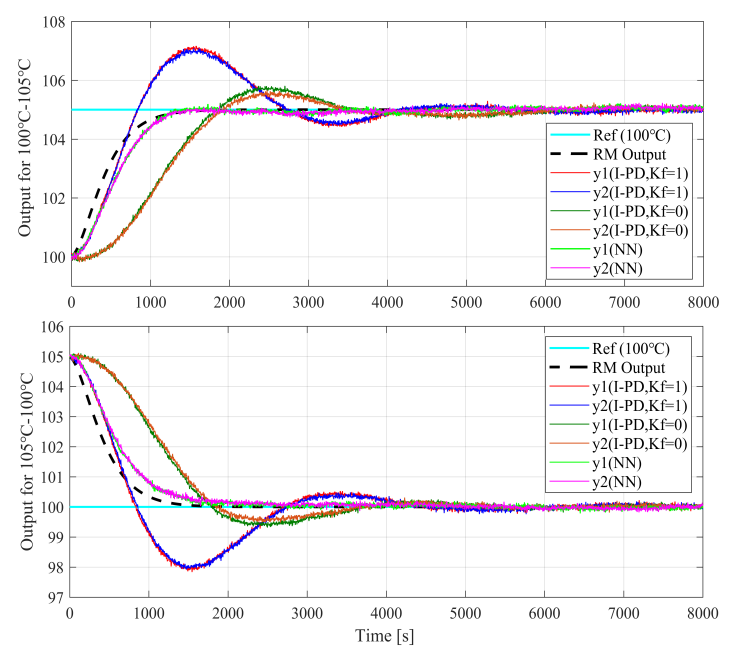

(b) Positive and negative direction control results.

Figure 11. Experimental results. (a) Time response for the controlled system. (b) Results of positive direction control for the temperature from $100{ }^{\circ} \mathrm{C}$ to $105^{\circ} \mathrm{C}$ and negative direction control for the temperature from $105^{\circ} \mathrm{C}$ to $100{ }^{\circ} \mathrm{C}$.

In the negative direction, similar results can be obtained. The rise time of ch1 and ch2 in the I-PD $\left(K_{f}=0\right)$ control system is $1027.3 \mathrm{~s}$ and $1093.4 \mathrm{~s}$, in the NN control system is $877.3 \mathrm{~s}$ and $893.7 \mathrm{~s}$, which has been improved by $14.6 \%$ and $18.3 \%$. The settling time of ch1 and ch2 in the I-PD $\left(K_{f}=0\right)$ control system is $3492.7 \mathrm{~s}$ and $3325.1 \mathrm{~s}$, the $\mathrm{NN}$ control system has an improvement of $38.6 \%$ and $37 \%$, which is $2145.6 \mathrm{~s}$ and $2093.2 \mathrm{~s}$, respectively. In the I-PD $\left(K_{f}=1\right)$ control system, the settling time of ch1 and ch 2 is $3862.5 \mathrm{~s}$ and $3870.4 \mathrm{~s}$. By comparison, the NN control system improved by $44.5 \%$ and $45.9 \%$, respectively. In addition, the overshoots of ch1 and ch2 in the I-PD $\left(K_{f}=1\right)$ control system are about $2.14{ }^{\circ} \mathrm{C}$ and $2.07{ }^{\circ} \mathrm{C}$, corresponding to $42.7 \%$ and $41.4 \%$ of the reference. The overshoots in the I-PD $\left(K_{f}=0\right)$ control system are $0.62{ }^{\circ} \mathrm{C}$ and $0.48{ }^{\circ} \mathrm{C}$, corresponding to $12.3 \%$ and $9.7 \%$ of the reference. In the $\mathrm{NN}$ control system, the overshoots of ch1 and ch2 are about $0.11{ }^{\circ} \mathrm{C}$ and 0.12 ${ }^{\circ} \mathrm{C}$, which are $2.1 \%$ and $2.5 \%$ of the reference. The overshoots in both directions are much smaller than the results of the I-PD control systems. Two channels can track the reference model output, realizing a quick and stable response to temperature signals. Comparing experimental results of the system response in Figure 11 with the simulation results in Figure 8, the discrepancy between the real system performance and simulation within $5 \%$ either settling time or overshoot, e.g., the errors of the NN system for the positive direction are about $2.3 \%$ and $1.7 \%$ in settling time and $1.3 \%$ and $1.7 \%$ in overshoot, respectively, the negative direction results are about $4.3 \%$ and $3.3 \%$ in settling time and $2.1 \%$ and $2.5 \%$ in overshoot. The corresponding errors of the I-PD control systems are slightly larger than $5 \%$, e.g., the errors of the I-PD $\left(K_{f}=0\right)$ system for the negative direction are about $5.3 \%$ and $5.7 \%$ in settling time, respectively, the I-PD $\left(K_{f}=1\right)$ system errors are about $5.1 \%$ and $8.2 \%$. Although the errors of rise time are about $10 \%$ in both directions, considering the difference between different 
channels is almost negligible, results are acceptable. These results show a good agreement between simulated and experimental results.

For comparison, the response characteristics of different control systems in positive and negative directions are listed in Tables 3 and 4, respectively. The percentage differences between the experimental results and simulation results are also given in both tables. From the above experimental results, it is seen that the proposed $\mathrm{NN}$ control gives great improvement in the performance of the temperature system.

Table 3. Comparison of experimental results for time response characteristics $\left(100{ }^{\circ} \mathrm{C}\right.$ to $\left.105^{\circ} \mathrm{C}\right)$.

\begin{tabular}{cccccccc}
\hline Characteristics & Ref & CH1 $\left(\boldsymbol{K}_{f}=\mathbf{1}\right)$ & $\mathbf{C H 2}\left(\boldsymbol{K}_{\boldsymbol{f}}=\mathbf{1}\right)$ & $\mathbf{C H 1}\left(\boldsymbol{K}_{\boldsymbol{f}}=\mathbf{0}\right)$ & $\mathbf{C H 2}\left(\boldsymbol{K}_{\boldsymbol{f}}=\mathbf{0}\right)$ & $\mathbf{C H 1}(\mathrm{NN})$ & $\mathbf{C H 2}(\mathrm{NN})$ \\
\hline Rise Time $(\mathrm{s})$ & 780.7 & $534.9(14.1 \%)$ & $557.6(13.4 \%)$ & $947.2(1.7 \%)$ & $973.1(1.7 \%)$ & $812.4(11.6 \%)$ & $820.6(4.1 \%)$ \\
\hline SettlingTime $5 \%(\mathrm{~s})$ & 1378.2 & $3824.3(4.2 \%)$ & $3718.6(4.4 \%)$ & $3414.2(6.1 \%)$ & $3217.9(2.3 \%)$ & $2217.3(2.3 \%)$ & $2204.8(1.7 \%)$ \\
\hline Overshoot $(\%)$ & 0 & $40.1(4.8 \%)$ & $38.4(3.4 \%)$ & $13.9(3.9 \%)$ & $10.5(2.5 \%)$ & $1.3(1.3 \%)$ & $1.7(1.7 \%)$ \\
\hline
\end{tabular}

Table 4. Comparison of experimental results for time response characteristics $\left(105^{\circ} \mathrm{C}\right.$ to $\left.100{ }^{\circ} \mathrm{C}\right)$.

\begin{tabular}{cccccccc}
\hline Characteristics & Ref & $\mathbf{C H 1}\left(\boldsymbol{K}_{f}=\mathbf{1}\right)$ & $\mathbf{C H 2}\left(\boldsymbol{K}_{f}=\mathbf{1}\right)$ & $\mathbf{C H 1}\left(\boldsymbol{K}_{f}=\mathbf{0}\right)$ & $\mathbf{C H} \mathbf{2}\left(\boldsymbol{K}_{f}=\mathbf{0}\right)$ & $\mathbf{C H 1}(\mathrm{NN})$ & $\mathbf{C H} \mathbf{( N N )}$ \\
\hline Rise Time $(\mathrm{s})$ & 780.7 & $519.1(11.5 \%)$ & $535.5(9.8 \%)$ & $1027.3(9.3 \%)$ & $1093.4(9.4 \%)$ & $877.3(17.1 \%)$ & $893.7(13.6 \%)$ \\
\hline SettlingTime $5 \%(\mathrm{~s})$ & 1378.2 & $3862.5(5.1 \%)$ & $3870.4(8.2 \%)$ & $3492.7(5.3 \%)$ & $3325.1(5.7 \%)$ & $2145.6(4.3 \%)$ & $2093.2(3.3 \%)$ \\
\hline Overshoot $(\%)$ & 0 & $42.7(5.9 \%)$ & $41.4(6.1 \%)$ & $12.3(2.2 \%)$ & $9.7(1.8 \%)$ & $2.1(2.1 \%)$ & $2.5(2.5 \%)$ \\
\hline
\end{tabular}

Figure 12a,b show the curves of temperature differences between the outputs of ch1 and ch2 in positive and negative directions, respectively. In the positive direction, the maximum temperature differences of the I-PD $\left(K_{f}=1\right)$, I-PD $\left(K_{f}=0\right)$, and $\mathrm{NN}$ control are $0.39{ }^{\circ} \mathrm{C}, 0.43{ }^{\circ} \mathrm{C}$, and $0.15{ }^{\circ} \mathrm{C}$, which correspond to $6.4 \%, 9.4 \%$, and $3.8 \%$ of the reference value, respectively. In addition, the time for the temperature difference drops to $0{ }^{\circ} \mathrm{C}$ is about $3900 \mathrm{~s}, 3600 \mathrm{~s}$, and $2300 \mathrm{~s}$. The NN control system has an improvement of $41 \%$ and $36 \%$ compared to the I-PD $\left(K_{f}=1\right)$ and I-PD $\left(K_{f}=0\right)$ control system, respectively. As illustrated in Figure 12a, the temperature difference of the NN control system can be suppressed by the proposed method.

Similarly, in the negative direction, the maximum absolute temperature differences of the I-PD $\left(K_{f}=1\right)$, I-PD $\left(K_{f}=0\right)$, and $\mathrm{NN}$ control systems are $0.24{ }^{\circ} \mathrm{C}, 0.25{ }^{\circ} \mathrm{C}$, and $0.14{ }^{\circ} \mathrm{C}$, corresponding to $4.8 \%, 5 \%$, and $2.8 \%$ of the reference value. Moreover, the time for the temperature difference drops to $0{ }^{\circ} \mathrm{C}$ is about $4400 \mathrm{~s}, 4100 \mathrm{~s}$, and $3300 \mathrm{~s}$, respectively. The $\mathrm{NN}$ control system has an improvement of $25 \%$ and $20 \%$ compared to the I-PD $\left(K_{f}=1\right)$ and I-PD $\left(K_{f}=0\right)$ control system, respectively. From these results, it was observed that the rapid uniform temperature response could be achieved in both transient state and steady state. The proposed control method improved the performance of the multi-input multi-output temperature system.

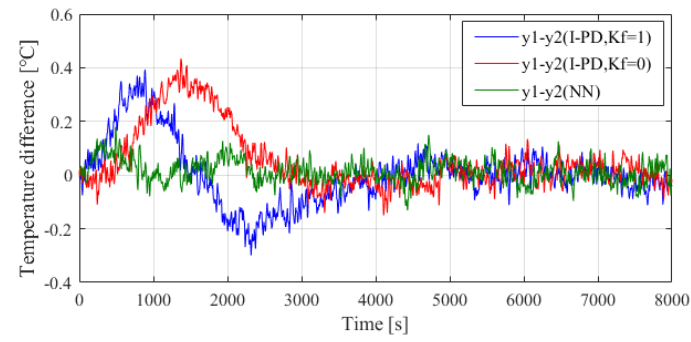

(a) Temperature difference $\left(100^{\circ} \mathrm{C}-105^{\circ} \mathrm{C}\right)$.

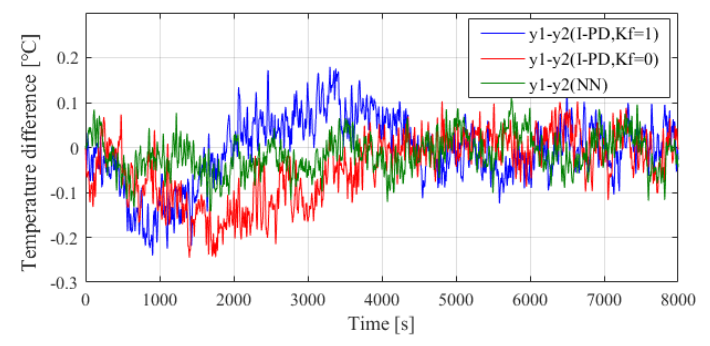

(b) Temperature difference $\left(105^{\circ} \mathrm{C}-100^{\circ} \mathrm{C}\right)$.

Figure 12. Experimental results. (a) Temperature differences between ch 1 and $\mathrm{ch} 2$ from $100{ }^{\circ} \mathrm{C}$ to $105^{\circ} \mathrm{C}$. (b) Temperature differences between ch1 and ch2 from $105^{\circ} \mathrm{C}$ to $100{ }^{\circ} \mathrm{C}$. 


\section{Conclusions}

In this paper, to improve transient response and realize the temperature uniformity in the multi-input multi-output temperature system with strong coupling effects, a reference-model-based neural network control method was proposed. In order to confirm the effectiveness of the proposed method, the proposed NN method was applied to a real MIMO temperature control system. Simulation and experiments were carried out, respectively. Both simulation results and experimental results were quantitatively compared with those of the I-PD control systems. The improvement of the transient response was achieved from the above experimental results, e.g., $42 \%$ and $40.7 \%$ improvements of two channels in settling time shortening compared to those of the traditional I-PD $\left(K_{f}=1\right)$ control system. In addition, the overshoots of different channels decreased by about $40 \%$ in both directions. The temperature uniformity of the MIMO system was achieved, e.g., in the positive direction, the temperature differences between two channels were reduced in more than half of those in the I-PD $\left(K_{f}=1\right)$ and I-PD $\left(K_{f}=0\right)$ control system. The temperature differences quickly went down to zero, with about $41 \%$ and $36 \%$ improvements in time compared to the I-PD control systems, respectively. These results show that the proposed NN control method improved the transient response and overshoot of the multi-input multi-output temperature system and realized the temperature uniformity of different channels in both transient state and steady state. The control effectiveness of the proposed method was successfully verified. For the NN control learning in the MIMO system, the selection of inputs and teaching signal is worth discussing in future study, e.g., the temperature difference between channels or derivative of difference can be added to inputs of the NN controller, thus it is possible to further improve the control performance.

Author Contributions: Conceptualization, S.H. and Y.L.; methodology, S.H.; software, S.H.; validation, Y.L., S.H. and S.X.; formal analysis, S.H. and Y.L.; investigation, S.H.; resources, S.H.; data curation, Y.L. and S.X.; writing-original draft preparation, Y.L.; writing-review and editing, S.X. and S.H.; visualization, S.H. and T.K.; supervision, S.H. and T.K.; project administration, S.H. and T.K.; funding acquisition, S.H. All authors have read and agreed to the published version of the manuscript.

Funding: This research received no external funding.

Conflicts of Interest: The authors declare no conflict of interest.

\section{References}

1. Johnson, M.A.; Moradi, M.H. PID Control; Springer-Verlag London Limited: London, UK, 2005.

2. Åström, K.J.; Hägglund, T. Revisiting the Ziegler-Nichols step response method for PID control. J. Process. Control 2004, 14, 635-650. [CrossRef]

3. Wang, Y.J.; Huang, S.T.; You, K.H. Calculation of robust and optimal fractional PID controllers for time delay systems with gain margin and phase margin specifications. In Proceedings of the 201736 th Chinese Control Conference (CCC), Dalian, China, 26-28 July 2017; pp. 3077-3082.

4. Jacob, J.; Das, S.; Khaneja, N. A Concise Method of Pole Placement to Stabilize the Linear Time Invariant MIMO System. In Proceedings of the Sixth Indian Control Conference (ICC), Hyderabad, India, 18-20 December 2019; pp. 35-39.

5. Singh, J.; Chattterjee, K.; Vishwakarma, C.B. Two degree of freedom internal model control-PID design for LFC of power systems via logarithmic approximations. ISA Trans. 2018, 72, 185-196. [CrossRef] [PubMed]

6. Kurniawan, A.M.; Handogo, R.; Sutikno, J.P.; Lee, H.Y. Stability Criterion of Modified Inverse Nyquist Array on a Simple Non-square MIMO Process. Int. J. Appl. Chem. 2018, 14, 293-310.

7. Karbakhsh, F.; Gharehpetian, G.B.; Milimonfared, J.; Teymoori, A. Three phase photovoltaic grid-tied inverter based on feed-forward decoupling control using fuzzy-PI controller. In Proceedings of the 7th Power Electronics and Drive Systems Technologies Conference,Tehran, Iran, 16-18 February 2016; pp. 344-348.

8. Chen, P.Y.; Zhang, W.D. Improvement on an inverted decoupling technique for a class of stable linear multivariable processes. ISA Trans. 2007, 46, 199-210. [CrossRef] [PubMed]

9. Tuhta, S.; Günday, F.; Aydin, H.; Alalou, M. MIMO System Identification of MachineFoundation Using N4SID. Int. J. Interdiscip. Innov. Res. Dev. (IJIIRD) 2019, 4, 27-36. 
10. Sands, T. Nonlinear-Adaptive Mathematical System Identification. Computation 2017, 5, 47. [CrossRef]

11. Valarmathi, R.; Guruprasath, M. System identification for a MIMO process. In Proceedings of the 2017 International Conference on Computation of Power, Energy Information and Commuincation, Melmaruvathur, India, 22-23 March 2017; pp. 435-441.

12. Suenaga, Y.; Matsunaga, N.; Kawaji, S. An Uniform Temperature Control on Thermal Conduction Surface by Gradient Control Method. In Proceedings of the 22nd SICE Kyusyu Branch Annual Conference, Fukui, Japan, 4-6 August 2003; pp. 243-246.

13. Mac Thi, T.; Copot, C.; De Keyser, R.; Tran, T.D.; Vu, T. MIMO fuzzy control for autonomous mobile robot. J. Autom. Control Eng. 2016, 4, 65-70. [CrossRef]

14. Sindhwani, N.; Bhamrah, M.S.; Garg, A.; Kumar, D. Performance analysis of particle swarm optimization and genetic algorithm in MIMO systems. In Proceedings of the 8th International Conference on Computing, Communication and Networking Technologies (ICCCNT), Delhi, India, 3-5 July 2017; pp. 1-6.

15. Slama, S.; Errachdi, A.; Benrejeb, M. Model reference adaptive control for MIMO nonlinear systems using RBF neural networks. In Proceedings of the 2018 International Conference on Advanced Systems and Electric Technologies, Hammamet, Tunisia, 22-25 March 2018; pp. 346-351.

16. Han, H.G.; Guo, Y.N.; Qiao, J.F. Nonlinear system modeling using a self-organizing recurrent radial basis function neural network. Appl. Soft Comput. 2018, 71, 1105-1116. [CrossRef]

17. Liu, W.; Wang, Z.; Liu, X.; Zeng, N. A survey of deep neural network architectures and their applications. Neurocomputing 2017, 234, 11-26. [CrossRef]

18. Baek, M.S.; Kwak, S.; Jung, J.Y.; Kim, H.M.; Choi, D.J. Implementation methodologies of deep learning-based signal detection for conventional MIMO transmitters. IEEE Trans. Broadcast. 2019, 65, 636-642. [CrossRef]

19. Sundermeyer, M.; Schlüter, R.; Ney, H. LSTM neural networks for language modeling. In Proceedings of the Thirteenth Annual Conference of the International Speech Communication Association, Portland, OR, USA, 9-13 September 2012.

20. Ryu, S.H.; Moon, H.J. Development of an occupancy prediction model using indoor environmental data based on machine learning techniques. Build. Environ. 2016, 107, 1-9. [CrossRef]

21. Esfe, M.H.; Razi, P.; Hajmohammad, M.H.; Rostamian, S.H.; Sarsam, W.S.; Arani, A.A.A.; Dahari, M. Optimization, modeling and accurate prediction of thermal conductivity and dynamic viscosity of stabilized ethylene glycol and water mixture Al2O3 nanofluids by NSGA-II using ANN. Int. Commun. Heat Mass Transf. 2017, 82, 154-160. [CrossRef]

22. Ghritlahre, H.K.; Prasad, R.K. Prediction of thermal performance of unidirectional flow porous bed solar air heater with optimal training function using artificial neural network. Energy Procedia 2017, 109, 369-376. [CrossRef]

23. Shen, C.; Song, R.; Li, J.; Zhang, X.; Tang, J.; Shi, Y.; Liu, J.; Cao, H. Temperature drift modeling of MEMS gyroscope based on genetic-Elman neural network. Mech. Syst. Signal Process. 2016, 72, 897-905.

24. Li, X.; Zhao, T.; Zhang, J.; Chen, T. Predication control for indoor temperature time-delay using Elman neural network in variable air volume system. Energy Build. 2017, 154, 545-552. [CrossRef]

25. Katic, K.; Li, R.L.; Verharrt, J.; Zeiler, W. Neural network based predictive control of personalized heating systems. Energy Build. 2018, 174, 199-213. [CrossRef]

26. Carvalho, C.B.; Carvalho, E.P.; Ravagnani, M.A. Implementation of a neural network MPC for heat exchanger network temperature control. Braz. J. Chem. Eng. 2020, 1-16, doi:10.1007/s43153-020-00058-2. [CrossRef]

27. Hashimoto, S.; Xu, S.; Jiang, Y.; Nishizawa, Y. AI-Based Feedback Control Applicable to Process Control Systems. In Proceedings of the International Conference on Mechanical, Electrical and Medical Intelligent System, Kiryu, Japan, 4-6 December 2019.

28. Xu, S.; Hashimoto, S.; Jiang, W. A Novel Reference Model-Based Neural Network Approach to Temperature Control System. In Proceedings of the IOP Conference Series: Materials Science and Engineering, Wuhan, China, 10-12 October 2019.

29. Wu, S.; Zhang, R.; Lu, R.; Gao, F. Design of dynamic matrix control based PID for residual oil outlet temperature in a coke furnace. Chemom. Intell. Lab. Syst. 2014, 134, 110-117. [CrossRef]

30. Rajinikanth, V.; Latha, K. I-PD controller tuning for unstable system using bacterial foraging algorithm: A study based on various error criterion. Appl. Comput. Intell. Soft Comput. 2012, 2012. [CrossRef]

31. Hameed, A.A.; Karlik, B.; Salman, M.S. Back-propagation algorithm with variable adaptive momentum. Knowl. Based Syst. 2019, 114, 79-87. [CrossRef] 
32. Ozbay, Y.; Karlik, B. A fast training back-propagation algorithm on windows. In Proceedings of the 3rd International Symposium on Mathematical and Computational Applications, Konya, Turkey, 4 September 2002; pp. 204-210.

33. Agarap, A.F. Deep learning using rectified linear units (relu). arXiv 2018, arXiv:1803.08375.

34. Salas, A.H. The exponential function as a limit. Appl. Math. Sci. 2012, 91, 4519-4526.

35. Chetouani, Y. Using ARX approach for modelling and prediction of the dynamics of a reactor-exchanger. Inst. Chem. Eng. Symp. Ser. 2008, 154, 297.

36. Batlle, C.; Roqueiro, N. Balanced model order reduction for systems depending on a parameter. arXiv 2016, arXiv:1604.08086.

Publisher's Note: MDPI stays neutral with regard to jurisdictional claims in published maps and institutional affiliations.

(c) 2020 by the authors. Licensee MDPI, Basel, Switzerland. This article is an open access article distributed under the terms and conditions of the Creative Commons Attribution (CC BY) license (http:// creativecommons.org/licenses/by/4.0/). 